\title{
Dynamic Behavior of Pavement Layers on Sand Subgrade
}

\author{
Mariam M. Hussein ${ }^{\mathbb{D}}$, Mohammed Y. Fattah ${ }^{\mathbb{D}}$, Miami M. Hilal $\mathbb{D}$ \\ Civil Engineering Dept., University of Technology-Iraq, Alsina'a street,10066 Baghdad, Iraq. \\ *Corresponding author Email: mailto:maryammousa791@gmail.com
}

\section{H I G H L I G H T S}

- The experimental work contains of pavement layers on a sand subgrade under the effect of earthquake.

- The pavement layers are tested under the influence of earthquake loading with different frequencies.

- The tests consist of two parts without adding the geogrid, and with geogrid.

- Stresses in the three layers are measured and displacements of the asphalt layer.

- For models reinforced with geogrid, the stress recorded is higher than in unreinforced models.

\section{A R T I C L E I N F O}

Handling editor: Wasan I. Khalil

Keywords:

Pavement layers

Geogrid reinforcement

Dynamic

Stresses

Displacements

\begin{abstract}
A B S T R A C T
Reinforcement interlayer reduces the development of cracks in the asphalt overlay by absorbing the stresses induced by heavy traffic or underlying cracking in the early-constructed pavement. This research is dedicated to studying the behavior of pavement layers on a sand subgrade under simulated effect of earthquake. In this study, the sand layer has a thickness of $600 \mathrm{~mm}$ and the base course is taken as $300 \mathrm{~mm}$. The asphalt layer was prepared as a panel with dimensions of $300 \times 300 \times 50$, which represents the surface layer. These layers are experimentally tested under the influence of earthquake loading with different frequencies $0.5,1,1.5 \mathrm{~Hz}$. The tests consist of two parts without adding the geogrid, with geogrid in the center of the base layer and between the base layer and sand layer. Loaded stresses in the three layers are monitored using stress gauge sensors, while displacements of the asphalt layer by using displacement gauge sensor. Obtained results considered models reinforced with geogrid, the stress recorded is higher than in unreinforced models but the displacement decreases by increasing the geogrid in the layers at three frequencies. When the geogrid is laid between the base course and sand layer, the stress in the sand subgrade layer is less than that in the base and asphalt layers.
\end{abstract}

\section{Introduction}

Composite material is basically a reinforced ground layer. These materials comprise ground base that is reinforced by layers of sheets or strips made of specific material capable to bear large tensile stress. The ground layer is usually cohesionless granular material, while the reinforcements are generally fabric sheets or metal strips (geotextile) laid down horizontally in the soil mass at certain intervals. The first function of the reinforcement is to tolerate the tensile stresses developed in the soil by means of interaction [1].

Implementation of geogrid in the construction industery in the form of a reinforcing material could be addressed as geosynthetic materials. It can be used in the reinforcement of retaining walls and even many applications of the material are on way to being flourished or utilized in the soil reinforcement. Geogrid has a high capacity to distribute load across a large area and the high demand and application of geogrid in construction are due to the reality that it is good in tension. The geosynthetic material, geogrids, is created employing intersecting grids which are polymeric products. Polymeric materials such as polypropylene are the primary composition of geogrids and polyester, high-density polyethylene.

Recently rehabilitating pavement systems and utilizing increased service life has become modern technologies to improve pavement performance as an important piece of design. Increasing pavement performance, toughness, and service life numerous these technologies may provide benefits, and one of these technologies is Pavement reinforcement [2].

Due to earthquakes, many cities of the world have suffered major economical and social relapses. Roads play an important role as a means to reach and rescue distressed people through emergencies like natural disasters and warfares and not only act 
as a mere path to transport commuters and goods. Many studies have been conducted regarding the danger analysis of structures, damage assessment, damage quantification, and vulnerability. But extremely limited researches are carried out in risk analysis of road/transport network and vulnerability. The convergent tectonic border among Eurasian and Arabian plates generates intense quake activity where Iraq lies in the northern part of the Arabian plate, bounded in the north and east by the Bitlis-Zagros fold-and-thrust belt. There was a great shake in Iraq and Mosul. Its influences were felt in Hamadhan.

Holder and Andreae [3] analyzed to evaluate the benefits of the geogrid reinforcement and analyzed the data from the falling weight deflectometer test (FWD). To evaluate the benefit of the geogrid reinforcement, the result of the analysis showed that a control section (unreinforced section) is critical.

Edil et al. [4] carried out the developed stiffness of granular layers reinforced with four types of geosynthetics, woven, geogrid, geotextile, geocomposite, and nonwoven geotextile large-scale model experiments that demonstrate. The results showed that unreinforced working platforms having the same thickness the working platforms reinforced with geosynthetics have smaller flexible deflections and larger flexible moduli.

Jeon [5] studied the test method that utilized the sorts of geogrids by utilizing integral geogrid and woven geogrid for appraising the long-term performance. The long-term deformation compared with the integral geogrid test results signalized that the woven geogrid had a powerful impedance. Estimated long-term creep deformation indicated that the 60-65\% of definitive loading level. The optimum values in the woven geogrid satisfy the crawl criteria.

Zorenberg [6] participated in Milam country, Texas their field experience on pavement over expansive soil. An extensive web on the pavement partition of longitudinal cracks was observed. Utilizing a layer of geogrid at the interface among the base and subgrade along with lime treated subgrade and asphalt seal coat on the top utilize of reinforcement was considered. In addition, a controlled (unreinforced) part to evaluate the influence of geogrid. Two geogrid reinforcement parts were constructed. Visual inspection of the pavement results showed that the control part was found to develop longitudinal cracks in with very short while falling weight deflectometer (FWD) testing was conducted to try to quantify the pavement performance period as where the two geo-grid reinforced sections were found to perform well, without any proof of longitudinal cracking.

Prasad et al. [7] by using the fly ash subbase courses laid on expansive soil subgrades, utilized various reinforcement materials. It was concluded that the optimum proportion of refuse plastics is equal to $0.4 \%$ for fly ash materials was observed from the laboratory test results of direct shear and CBR. By placing a circular mineral plate on paradigm flexible pavements. Cyclic load tests were carried out in the field. For geogrid reinforced stretch followed by bitumen coated bamboo mesh and waste plastics reinforced stretch in the flexible pavement laid on expansive subgrades, it was observed that the maximum loadcarrying ability related with less value of rebound deflection is acquired.

Choudhary et al. [8] used numerous layers of reinforcement within sub-grade namely geo-grid and jute geotextile. while the soil is reinforced with a single layer and goes on decreasing with an increase in the number of reinforcing layers. It was found that the extension proportion decrease but this reduction is significant in the status of jute geotextile and marginal in the status of geogrid which means the insertion of reinforcement controls swelling of the soil. Increase in the number of reinforcing layers, the California Bearing Ratio value of the soil also rises. Geogrid offers the best reinforcing efficiency than jute geotextile but it can be gainfully exploited in a depressed cost road project.

To research the response of an asphalt mixture quantitatively below a vibrating compaction load at the mesoscale, field laboratory tests were conducted by Dan et al. [9]. First, sensors (e.g., Smart-Rock and acceleration sensors) were utilized to gauge the dynamic response of asphalt pavement and vibrating drum through vibrating compaction and a field test program is designed. The first three rolling influences exert a significant and dominant compact influence on the asphalt mixture the quantitative analysis exposed. thereafter, a linear relationship among the vertical stress in the pavement was demonstrated and acceleration of vibrating drum. further, the relationship between the compaction grade and the vertical stress in the asphalt mixture is instituted, and Smart-Rock sensor is else exercised in the laboratory test to discover the internal dynamic response below gyratory compaction.

The aim of the laboratory testing program in this work is to inspect the dynamic response of pavement layers to earthquake excitation. The study will also discuss the influence of earthquake load on stress transfer in the pavement layers and the effect of frequency of earthquake load on the induced displacements and stresses between flexible pavement layers reinforced with geogrids.

\section{Experimental Work}

\subsection{General}

The experimental work consists of laboratory samples to understand the behavior of pavement layers on a sand subgrade under the effect of the earthquake. Then, geogrid reinforcement is put at different locations; at the interface between base course and sand, at the center of the base course, and below the asphalt layer. The stresses and displacements are measured by stress and displacement gauge sensors.

\subsection{Materials}

The soil that was used in this research as a subgrade layer is a naturalistic cohesionless soil (sand) imparted from Karbala city. A number of physical tests were conducted on it, the soil is classified as SP-SM soil according to the Unified Soil Classification System USCS (ASTM D2487-11) and according to AASHTO (ASTM D3282-09). The base course was selected from Al- Nibaee quarry, north of Baghdad. Generally, layers in flexible pavement build utilize this kind of base course. Crushed aggregates in this research are used, from Al-Nibaay quarry. It is greatly utilized in asphalt mixture produce. The physical properties were presented utilizing experiments (angularity, sieve analysis, flat and elongation, toughness by (Los 
Angeles abrasion), specific gravity, soundness, in addition to equivalent sand (clay content), as exhibited in Table 1 . Table 2 presents the gradation of aggregate for the base coarse according to the Iraqi specifications SCRB / 2003 (R7) used in this study.

In this study, one grade of asphalt cement is utilized which is (40 -50), according to the classification obtained from AlDaurah Refinery. The physical properties of asphalt cement are offered in Table 3.

\subsection{Pavement layer preparation}

To simulate the pavement layer, compacted asphalt mixture slabs are prepared. The slab dimensions are $300 \mathrm{~mm}$ width, $300 \mathrm{~mm}$ length, and $50 \mathrm{~mm}$ thickness, a steel model is utilized to compress the asphalt slab. Approximately 10522.4 gm of the asphalt mixture was prepared at optimum asphalt content (5.25\%) which was determined in previous studies [12], [13] to obtain asphalt slab with the mentioned dimensions, the asphalt mixture is laid uniformly in the oiled steel mold by utilizing a hot plated spatula, and then the surfaces are leveled.

The applied compression static load of $100 \mathrm{kN}$ is maintained for 6 minutes at $150^{\circ} \mathrm{C}$ to attain the same of Marshall specimen's bulk density equal to $2.32 \mathrm{~g} / \mathrm{cm}^{3}$ and the desired thickness is $50 \mathrm{~mm}$. The slab is left overnight then it is taken away from the mold and covered with polyethylene to avert any influence of environmental conditions on its properties as shown in Figure 1.

Table 1: Physical properties of aggregate.

\begin{tabular}{|c|c|c|c|c|c|c|}
\hline \multicolumn{2}{|l|}{ Laboratory Test } & \multirow[t]{2}{*}{$\begin{array}{l}\text { ASTM Designation and } \\
\text { Specification [10] }\end{array}$} & \multicolumn{4}{|l|}{ Result } \\
\hline \multirow{5}{*}{ Specific gravity } & \multirow{4}{*}{ Coarse aggregate } & & $\begin{array}{l}\text { Sieve size } \\
(\mathrm{mm})\end{array}$ & $\begin{array}{l}\text { Appar } \\
\text { ent Gs }\end{array}$ & $\begin{array}{l}\text { Bulk } \\
\text { Gs }\end{array}$ & Abs. $\%$ \\
\hline & & \multirow[t]{3}{*}{ ASTM C 127} & 12.5 & 2.674 & 2.651 & 0.32 \\
\hline & & & 9.5 & 2.591 & 2.585 & 0.09 \\
\hline & & & 4.75 & 2.582 & 2.570 & 0.18 \\
\hline & Fine aggregate & ASTM C 128 & $4.74-0.075$ & 2.642 & 2.615 & 0.48 \\
\hline \multicolumn{2}{|c|}{ Angularity for Coarse aggregate } & $\begin{array}{l}\text { ASTM D } 5821 \\
\text { Min } 95 \%\end{array}$ & \multicolumn{4}{|c|}{$97 \%$} \\
\hline \multicolumn{2}{|c|}{ Soundness for coarse aggregate } & $\begin{array}{l}\text { ASTM C } 88 \text { 10-20\% } \\
\text { Max }\end{array}$ & \multicolumn{4}{|c|}{$3.2 \%$} \\
\hline \multirow{2}{*}{$\begin{array}{l}\text { Equivalent sand } \\
\text { (clay content) }\end{array}$} & - Natural $(<\# 4)$ & ASTM D2419 & \multicolumn{4}{|c|}{$84.5 \%$} \\
\hline & Crushed $(<\# 4)$ & $\operatorname{Min} 45 \%$ & \multicolumn{4}{|c|}{$89.6 \%$} \\
\hline \multirow{2}{*}{$\begin{array}{l}\text { Flat \& Elongation } \\
\text { aggregate } \\
\text { Toughness by } \\
\text { (Los Angles } \\
\text { abrasion }\end{array}$} & $\begin{array}{l}\text { Flat } \\
\text { Elongation }\end{array}$ & $\begin{array}{l}\text { ASTM D } 4791 \\
\text { Max 10\% }\end{array}$ & \multicolumn{4}{|c|}{$0.9 \%$} \\
\hline & $\begin{array}{l}\text { Aggregate size }<25 \\
\mathrm{~mm}\end{array}$ & $\begin{array}{l}\text { ASTM C131 } \\
30 \% \operatorname{Max}\end{array}$ & \multicolumn{4}{|c|}{$21.3 \%$} \\
\hline
\end{tabular}

Table 2: Sieve analysis of base course.

\begin{tabular}{lllll}
\hline $\begin{array}{l}\text { Sieve Size } \\
(\mathbf{m m})\end{array}$ & $\begin{array}{l}\text { Cumulative Wt. } \\
\text { Retained }\end{array}$ & \% Retained & \% Passing & $\begin{array}{l}\text { Specification } \\
\text { Limits }\end{array}$ \\
\hline 37.5 & 0.0 & 0.0 & 100.0 & 100.0 \\
25.0 & 942.0 & 1.7 & 98.3 & $80-100$ \\
12.5 & 17860.0 & 32.1 & 67.9 & $50-80$ \\
4.75 & 29408.0 & 52.8 & 47.2 & $30-60$ \\
0.425 & 44642.0 & 80.1 & 19.9 & $10-30$ \\
0.075 & 51104.0 & 91.7 & 9.3 & $5-12$ \\
\hline
\end{tabular}

Table 3: Physical properties of asphalt cement.

\begin{tabular}{lll}
\hline Test & Result & $\begin{array}{l}\text { SCRB } \\
\text { Specifications [11] }\end{array}$ \\
\hline Penetration $\left(25^{\circ} \mathrm{C}, 100 \mathrm{~g}, 5 \mathrm{sec}\right)$ & 47 & $40-50$ \\
Ductility $\left(25^{\circ} \mathrm{C}, 5 \mathrm{~cm} / \mathrm{min}\right)$ & 110 & $\geq 100$ \\
Softening point $(\mathrm{ring} \& \mathrm{ball}){ }^{\circ} \mathrm{C}$ & 53 & - \\
Flash and fire point ${ }^{\circ} \mathrm{C}$ & 261,264 & $\geq 232$ \\
Loss on heating $\left(163^{\circ} \mathrm{C}, 50 \mathrm{gm}, 5 \mathrm{~h}\right) \%$ & 0.07 & $<0.75$ \\
Specific gravity asphalt & 1.049 & --- \\
Rotational Viscosity (Pas.sec.) & $0.6425 @ 135^{\circ} \mathrm{C}$ & --- \\
\hline
\end{tabular}




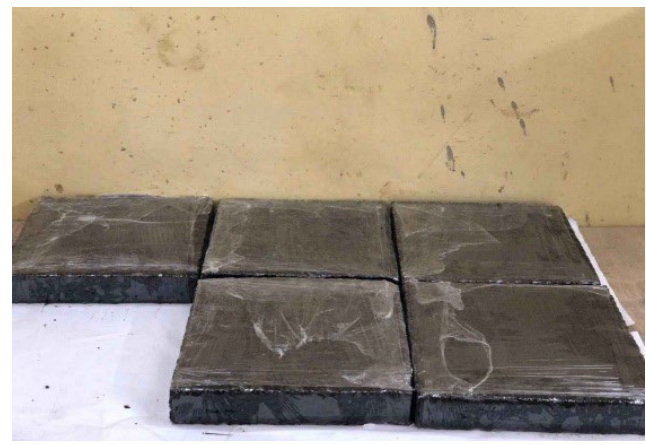

Figure 1: Asphalt slab models

\subsection{Thickness of the model layers}

The thickness of the selected layer depends on several pieces of research related to this study; the thickness of subgrade is chosen based on the work of [14], [15], and [16] which is $600 \mathrm{~mm}$, and the thickness of the base layer is $300 \mathrm{~mm}$ and the asphalt layer is $50 \mathrm{~mm}$. These dimensions are close to those adopted by Al-Utaby [14] and Tema [16]. Figure 2 shows the profile of pavement layers.

\subsection{Geogrid reinforcement}

Geogrid utilized in this work is type SS2 produced by QMOF CO (Quality Material for Oil Field) company in all tests as shown in Figure 3. The paper of geogrid was utilized in several experiences but was superseded whenever become overstressed or damaged.

\subsection{Shaking machine}

To simulate the earthquake excitation in the laboratory, various techniques can be followed; one of them is utilizing a shaking table. The shaking table is essential laboratory equipment that simulates the loading that happens during dynamic excitation as in an earthquake. The loading type can be harmonic, random, real earthquake movement, etc. The shaking table appliance consists from main four parts:

Shaking table base, electrical motor and Ac-drive, Steel box, and damping system. The shaking table was designed and manufactured by Al-Recaby [18] as shown in Figure 4. The steel box is placed on an L-shaped plate and linked between by a screw bolt $(15 \mathrm{~mm})$ in diameter. The steel box has internal dimensions $(800 \times 800 \times 1000) \mathrm{mm}$.

Tactile pressure sensors with $10 \mathrm{kPa}$ capacity were utilized to measure the stresses as shown in Figure 5. A laser displacement sensor was used to measure the space between the sensor and an object by disclosing the amount of displacement through a variety of elements and converting it into space. Two sensors are fixed to the model box on opposite sides to measure the horizontal displacement.

\subsection{Unreinforced models}

Before starting to apply earthquake, the bed of sand is placed in the steel container and the first sensor was placed at a depth of $50 \mathrm{~mm}$ under the surface of the sand. Then, the base course layer is placed above the subgrade and compacted manually by a steel hammer and leveled. The second sensor was put at deepness $50 \mathrm{~mm}$ below the middle of the base layer. Then, the slab specimen for the asphalt layer is placed on the base course and the third sensor was placed directly under the asphalt layer and a steel plate with dimensions $900 * 900 \mathrm{~mm}$ is placed on the asphalt layer as exhibited in Figure 6 to place the sensors.

\subsection{Reinforced models}

The SS2 geogrid layer is put on the surface of the sand layer, after the preparation of the bed of sandy soil. Then, the base course layer is laid with compaction, as mentioned previously, then the asphalt slab is placed on the base course layer. After that, the steps are repeated by changing the geogrid position and placing it once in the center of the base layer and once over the base layer. The first sensor was placed at deepness $50 \mathrm{~mm}$ below the surface of the sand, second sensor was placed at deepness $50 \mathrm{~mm}$ below the middle of base course layer and third sensor was placed directly under the asphalt layer. 


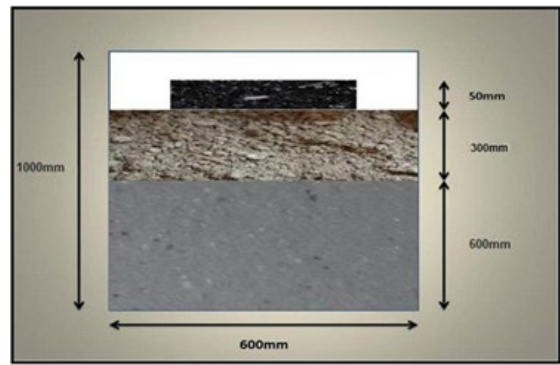

Figure 2: Profile of model layers

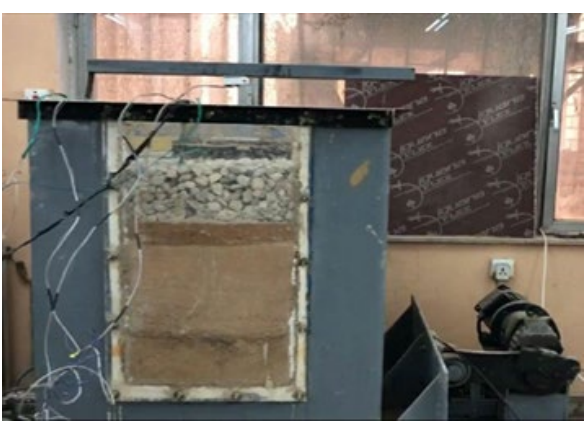

Figure 4: The shaking box

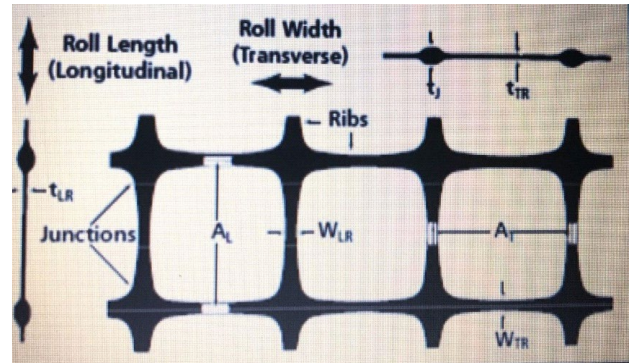

Figure 3: Dimension details of geogrid reinforcement [17]

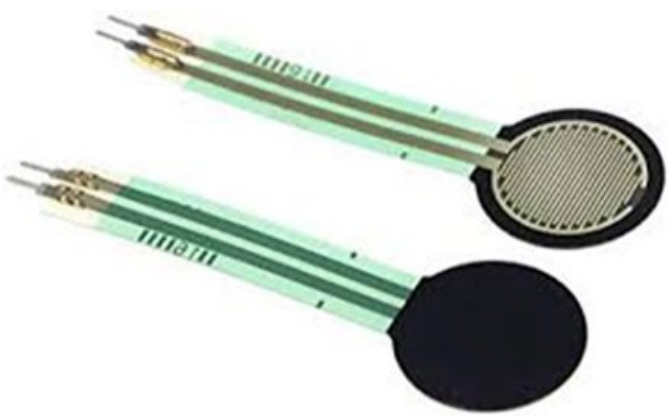

Figure 5: Stress gauge sensor

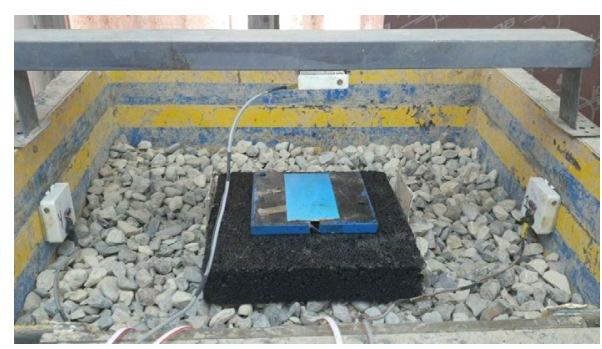

Figure 6: Pavement layers at unreinforced sample

\section{Results and Discussion}

\subsection{Stress and displacement results for the unreinforced models}

Figures 7 to 9 illustrate the vertical stress transferred to the base, base course, and asphalt layer under the dynamic load of $0.5,1,1.5 \mathrm{~Hz}$ frequencies respectively. Obviously as considered in these figures, the stress changes with raising the frequency. There is a rapid change for stress in the frequency $1.5 \mathrm{~Hz}$ compared to frequency 0.5 and $1 \mathrm{~Hz}$ where there is little change in these two cases. The maximum stress recorded at the frequency $1.5 \mathrm{~Hz}$ is higher than that at frequencies $0.5 \mathrm{and} 1 \mathrm{~Hz}$.

Figures 10 to 12 show the horizontal displacement measured under these loading conditions. From the data in the figures, the maximum displacement is recorded at frequency $1 \mathrm{~Hz}$ and the displacement at frequency 0.5 is low. It is noticed that there is the oscillation of displacement due to rapid movement; the displacement approximately becomes steady after about 80 seconds.

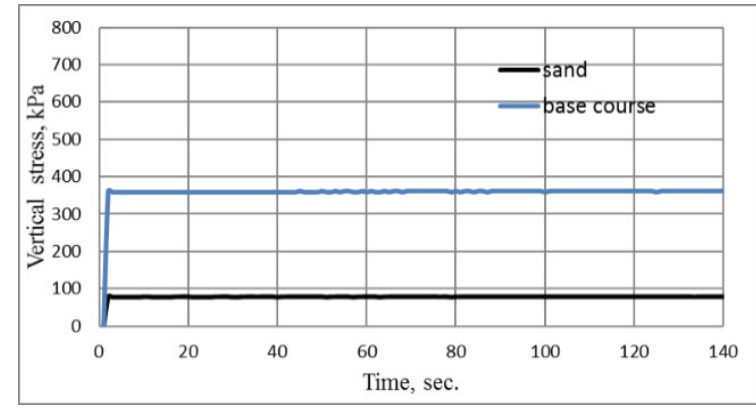

a. Base and subgrade

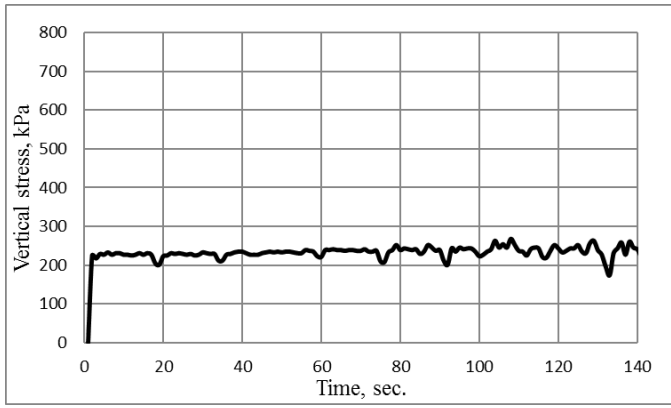

b. Asphalt

Figure 7: Variation of vertical stress in road layers under frequency $0.5 \mathrm{~Hz}$ 


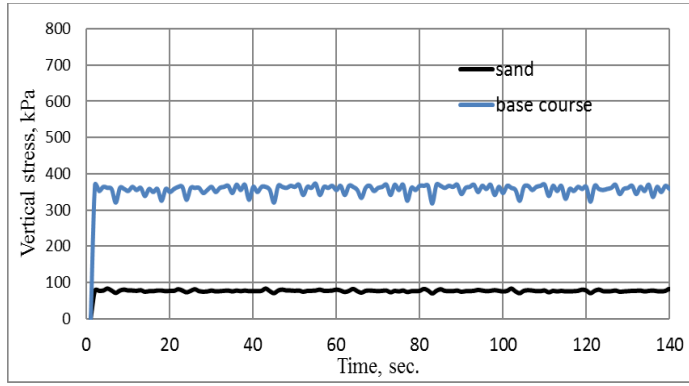

a. Base and subgrade

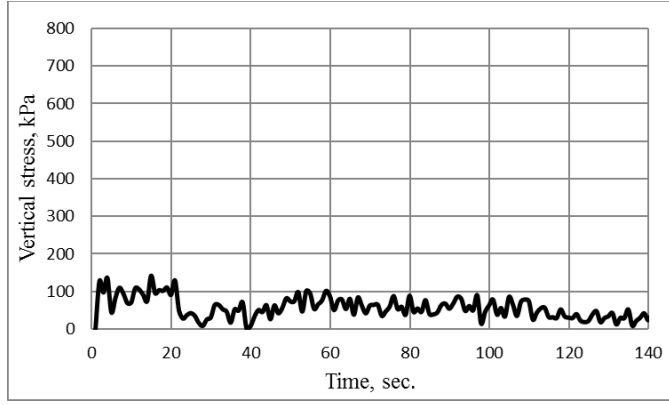

b. Asphalt

Figure 8: Variation of vertical stress in road layers under frequency $1 \mathrm{~Hz}$

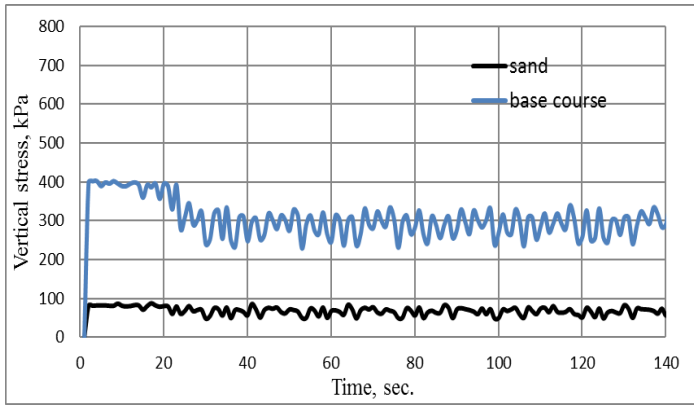

a. Base and subgrade

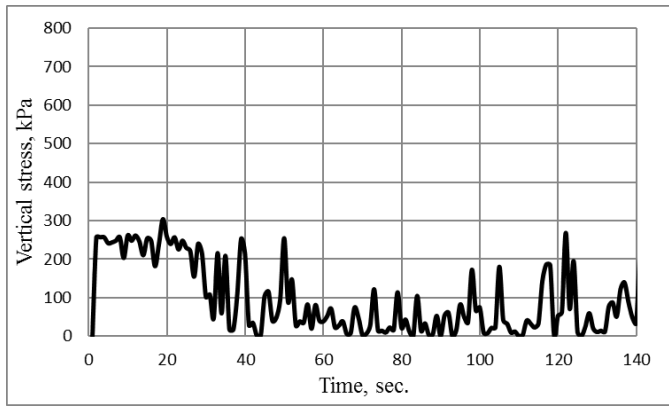

b. Asphalt

Figure 9: Variation of vertical stress in road layers under frequency $1.5 \mathrm{~Hz}$

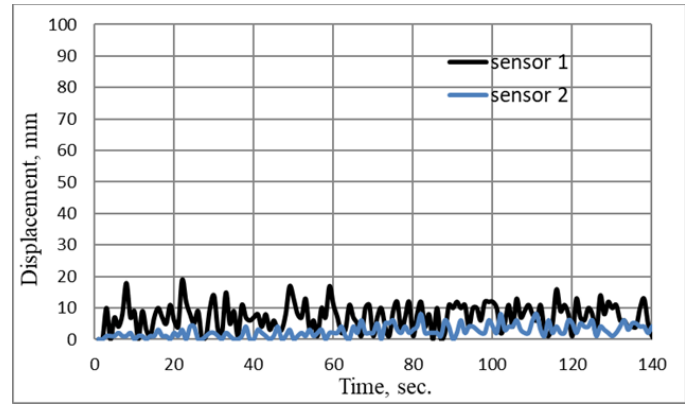

Figure 10: Variation of horizontal displacement in road layers under frequency $0.5 \mathrm{~Hz}$

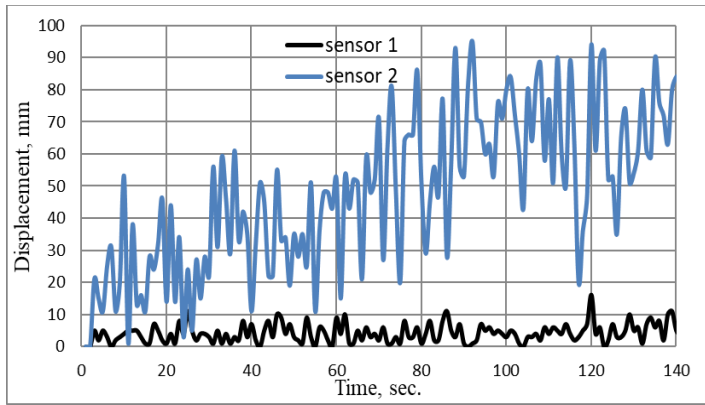

Figure 11: Variation of horizontal displacement in road layers under frequency $1 \mathrm{~Hz}$

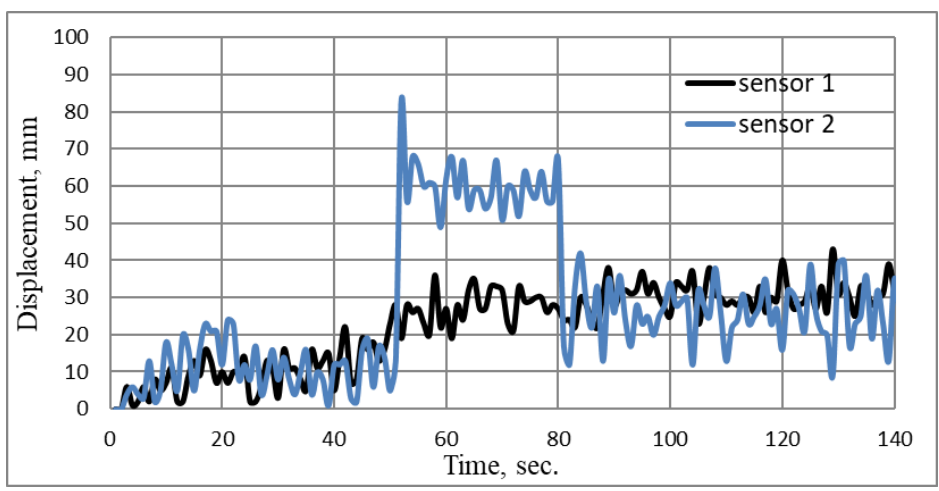

Figure 12: Variation of horizontal displacement in road layers under frequency $1.5 \mathrm{~Hz}$

\subsection{Stress and displacement results for the reinforced models}

Figures 13 to 18 illustrate the vertical stress transferred to the sand base, base course, and asphalt layer under the dynamic load of different frequencies. From the figures, if the geogrid is used in the middle of the base layer, the stress is less in the sand layer from the base course layer at frequencies $0.5,1$, and $1.5 \mathrm{~Hz}$. Through the results that are obtained, when the geogrid is laid between the base course and sand layer, the stress in the sand subgrade layer is less than that in the base and asphalt layers. When the geogrid is at the center of the base and between the base course and sand in the base course layer the maximum stress under the frequency $0.5 \mathrm{~Hz}$ occurs. While geogrid is placed at the center of the base occurs the maximum stress under the frequency is $1.5 \mathrm{~Hz}$ but the maximum stress under the frequency is $1.5 \mathrm{~Hz}$ when the geogrid is between the base and the sand occurs in the asphalt layer. 
The maximum stress at the frequency $1 \mathrm{~Hz}$ is higher than under frequencies 0.5 and $1.5 \mathrm{~Hz}$, when geogrid is laid at the center of the base course layer and between the base course and sand.

The distorted geogrid supplies a vertical upholding to the overlying soil mass display to loading, that is; the deformed geogrid, sustaining normal and shear stresses have a membrane force with a vertical component that withstands applied loads. This work of geogrid is on the whole known as its "membrane influence". Interlocking effect as stated by Fattah et al. [19], the utilize of geogrids has other benefits owing to the overlapping of the soil through the apertures (openings) between the longitudinal and transverse ribs.

From the figures, the stress while the geogrid is positioned at the middle of the base layer occurs under frequency $0.5 \mathrm{~Hz}$, it is lower than that in the unreinforced model under the same frequency by the rate of $9.1 \%$, and stresses under frequency $1 \mathrm{~Hz}$ with geogrid at the middle of the base are greater than those in the unreinforced model under the same frequency by about $42.3 \%$. Under the frequency $1.5 \mathrm{~Hz}$ for the model with geogrid at the center of the base course, stress is greater than that in the unreinforced model by only $0.2 \%$.

Fattah et al. [20] concluded that the influence of load frequency on the settlement proportion is almost constant next 500 cycles. Overall, for reinforced states, ranging between $0.5-2 \%$ compared with the unreinforced state the effect of load frequency on the settlement proportion is very little.

The maximum stress measured when the frequency is $0.5 \mathrm{~Hz}$ in a model with geogrid between the base and subgrade is greater than that in the unreinforced model under the same frequency by a rate of $48.2 \%$. Also under a frequency of $1 \mathrm{~Hz}$, for the model with geogrid between the base course and subgrade, the maximum stress is greater than that in the unreinforced model by a rate of $54.3 \%$. Finally, under frequency $1.5 \mathrm{~Hz}$ for models with geogrid between the base and subgrade, the maximum stress is greater than that measured in the unreinforced model by about $49.8 \%$.

Figures 19 to 24 show the horizontal displacement measured in the asphalt layer under these loading conditions. The displacement at frequency $1 \mathrm{~Hz}$ begins changing more than the frequency $0.5 \mathrm{~Hz}$, and under the frequency $1.5 \mathrm{~Hz}$., the displacement becomes more changing and increasing. The highest displacement is obtained at frequency $1.5 \mathrm{~Hz}$ when the geogrid is installed between the base course and the sand layer.

From the figures below, while the geogrid is at the center of the base course, under frequency $0.5 \mathrm{~Hz}$, the displacements are smaller than those measured in unreinforced models by a rate of $52.6 \%$. Also, the displacement when the geogrid is at the middle of the base course layer under frequency $1 \mathrm{~Hz}$ is greater than that in the unreinforced model by $85.2 \%$. In addition, under a frequency of $1.5 \mathrm{~Hz}$ in the model with geogrid at the center of the base course layer, the displacement is smaller than that measured in the unreinforced model.

When geogrid is placed among the base course and sand, the displacement recorded under frequency $0.5 \mathrm{~Hz}$ is smaller than that in the unreinforced model by about $47.3 \%$, but the displacement under frequency $1 \mathrm{~Hz}$ in the model with geogrid between the base course and subgrade is smaller than that in the unreinforced model by a rate of $89.4 \%$, but the displacement recorded under frequency $1.5 \mathrm{~Hz}$ in model with geogrid between base course and subgrade is increased than that in the unreinforced model by about $7.7 \%$.

In general, the soil without adding the geogrid is granular and behaves as a flexible layer. When the geogrid is added, an overlap occurs between the soil and geogrid, so the soil mass is working as one unit which increases the inertia force, thus making the stress increases in the layer. In addition, the geogrid stiffness is high, so the stresses become higher so that the stresses increase especially when increasing the loading frequency in the layers except when adding the geogrid in the center of the base layer under a frequency of $0.5 \mathrm{~Hz}$ where the stress became less.

Found the granular layers reinforced with geosynthetics reveal minimal elastic deflections and maximal elastic moduli than unreinforced action stands having the same thickness that these results are corresponding with those of Fattah et al. [19].

The values of horizontal displacement increase by increasing the loading frequency, as well as the horizontal displacement is faster and greater at $2 \mathrm{~Hz}$ of than 0.5 and $1 \mathrm{~Hz}$ in all cases as verified also by Fattah et al. [21] and Raheem et al. [22].

In Table 5, it is shown that the maximum displacement of the asphalt pavement layer decreases with the inclusion reinforcement in the layers because the geogrid reduces the motion of the asphalt layer.

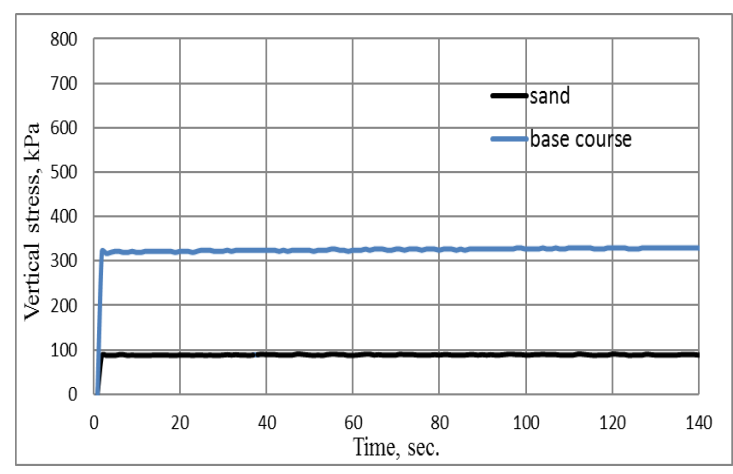

a. Base and subgrade

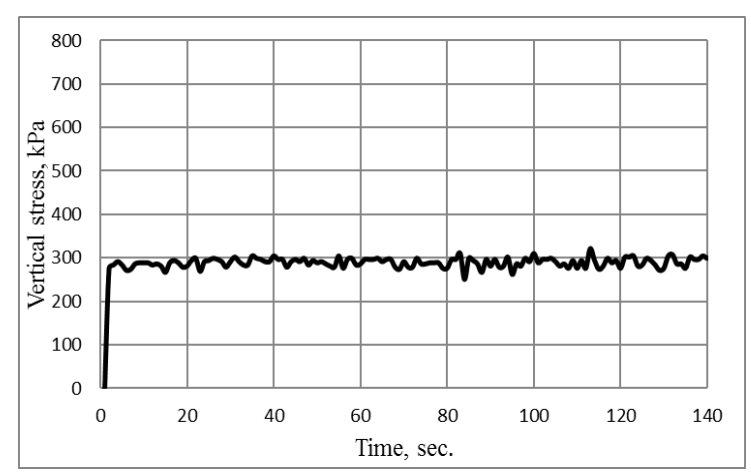

b. Asphalt

Figure 13: Variation of vertical stress in road layers under frequency $0.5 \mathrm{~Hz}, \mathrm{SS} 2$ geogrid at the center of base course layer 


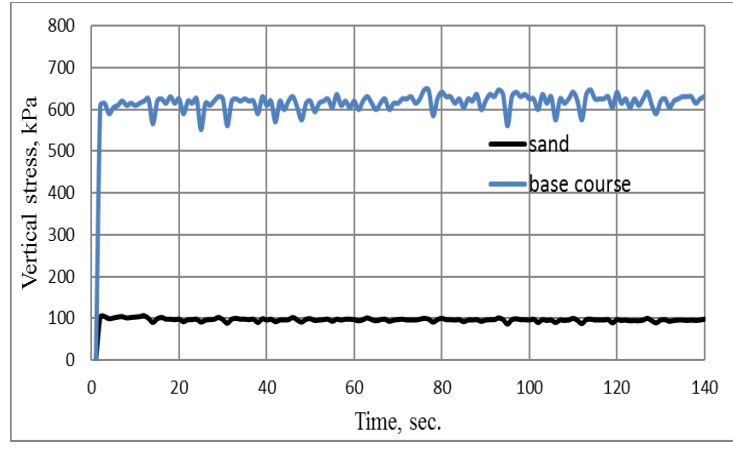

a. Base and subgrade

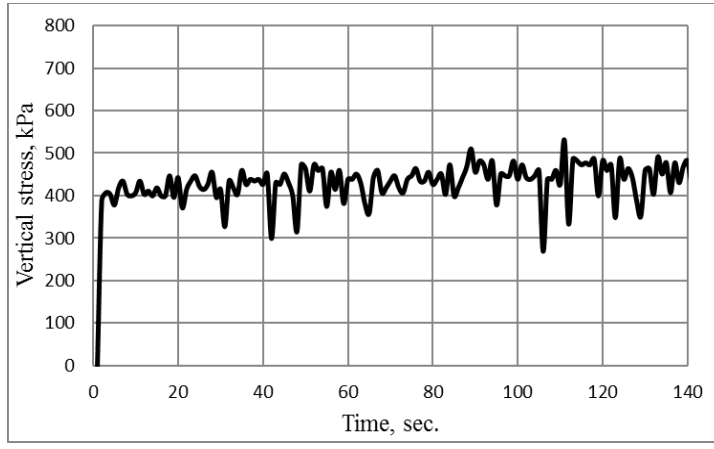

b. Asphalt

Figure 14: Variation of vertical stress in road layers under frequency $1 \mathrm{~Hz}, \mathrm{SS} 2$ geogrid at the center of base course layer

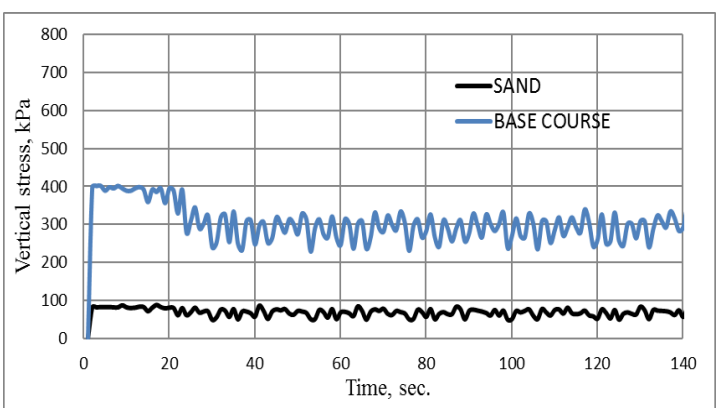

a. Base and subgrade

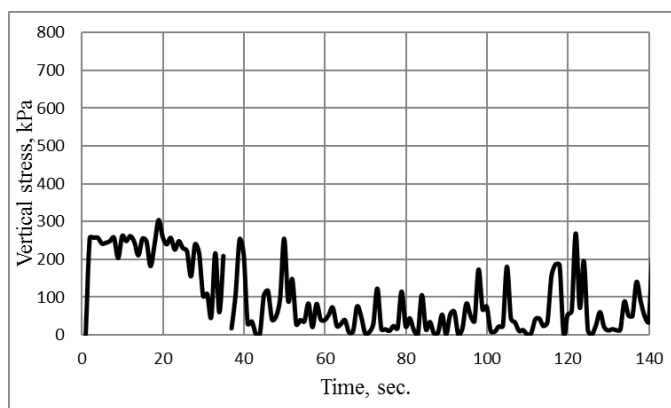

b. Asphalt

Figure 15: Variation of vertical stress in road layers under frequency $1.5 \mathrm{~Hz}$, SS2 geogrid at the center of base course.

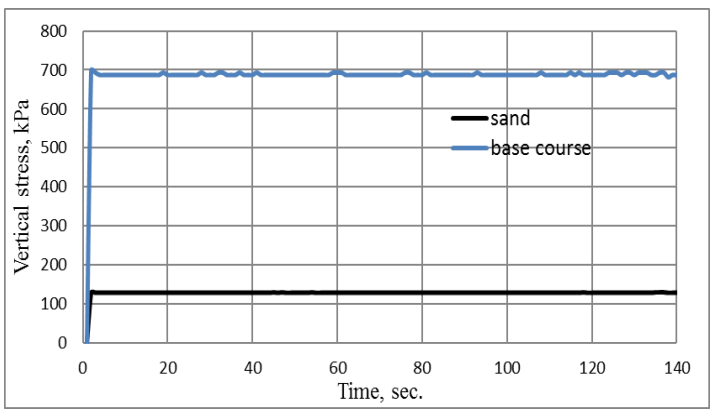

a. Base and subgrade

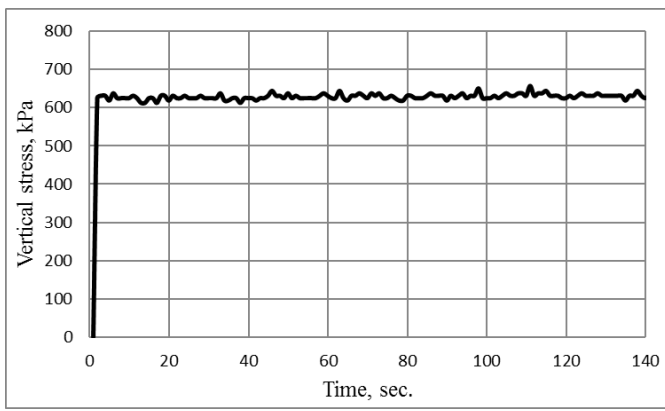

b. Asphalt

Figure 16: Variation of vertical stress in road layers under frequency $0.5 \mathrm{~Hz}, \mathrm{SS} 2$ geogrid between base course and sand.

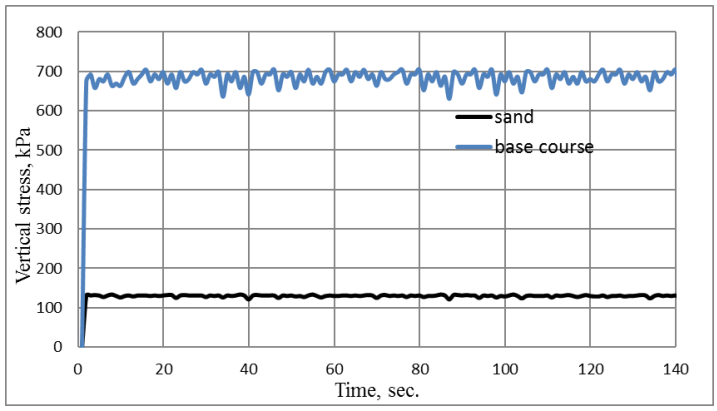

a. Base and subgrade

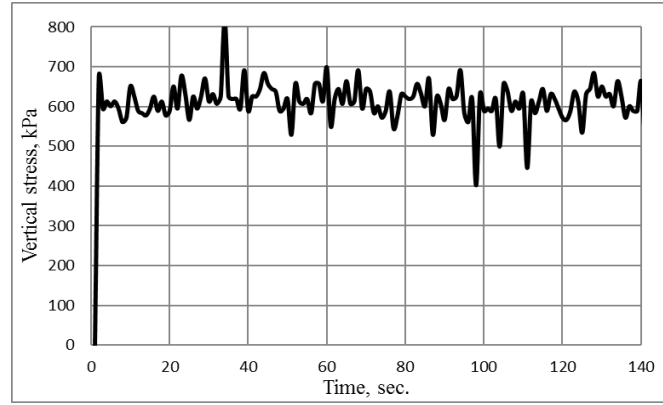

b. Asphalt

Figure 17: Variation of vertical stress in road layers under frequency $1 \mathrm{~Hz}, \mathrm{SS} 2$ geogrid between base course and sand. 


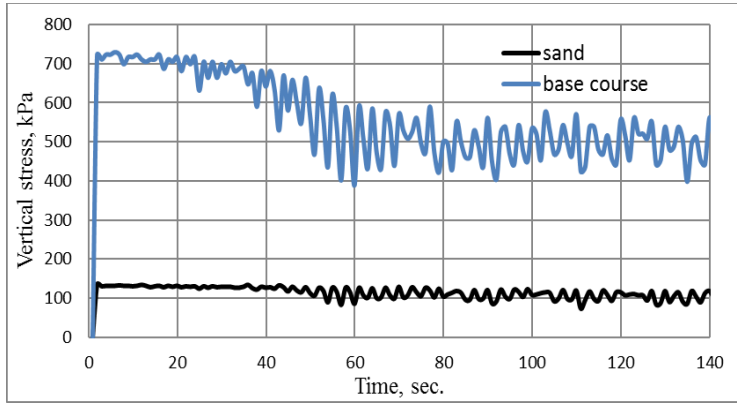

a. Base and subgrade

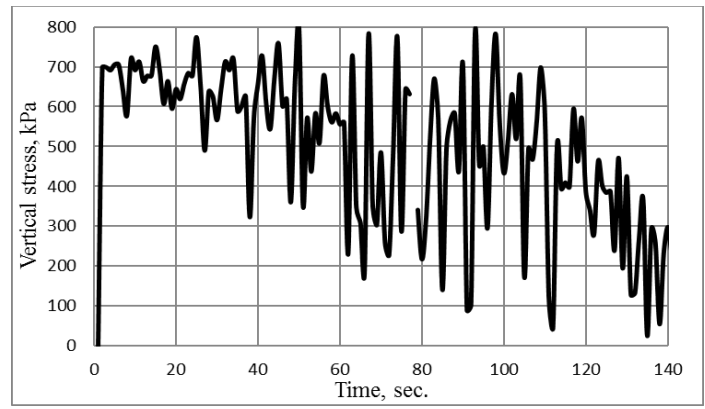

b. Asphalt

Figure 18: Variation of vertical stress in road layers under frequency $1.5 \mathrm{~Hz}, \mathrm{SS} 2$ geogrid between base course and sand.

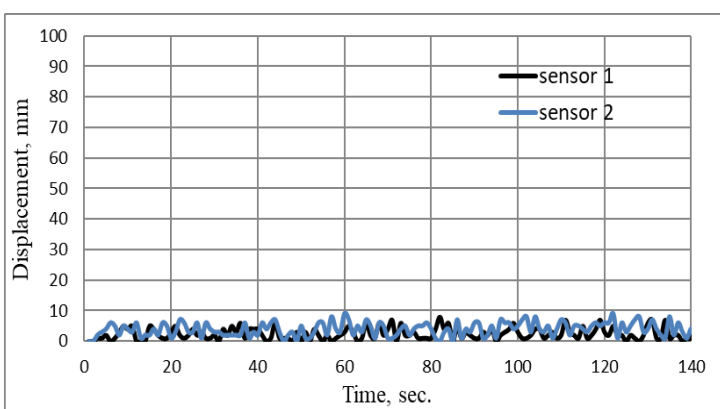

Figure 19: Variation of horizontal displacement in road layers under frequency $0.5 \mathrm{~Hz}$, SS2 geogrid at the center of base course layer

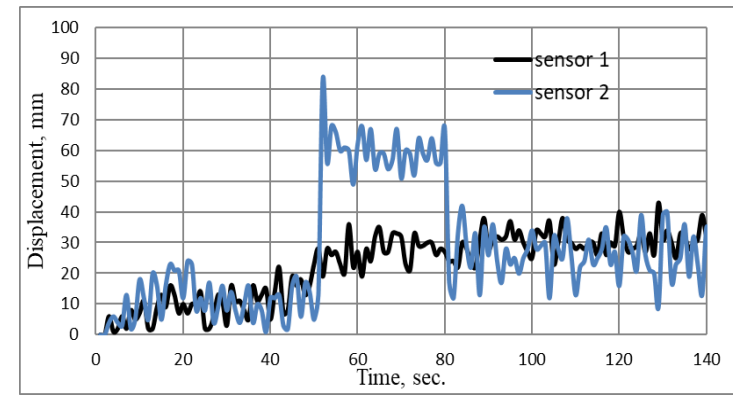

Figure 21: Variation of horizontal displacement in road layers under frequency $1.5 \mathrm{~Hz}, \mathrm{SS} 2$ geogrid at the center of base course layer

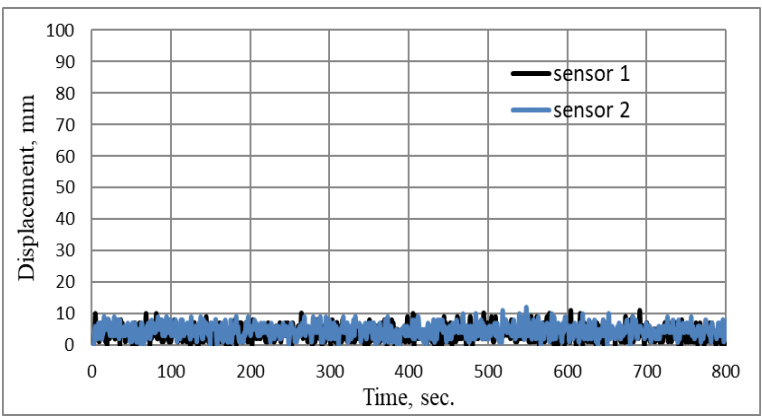

Figure 23: Variation of horizontal displacement in road layers under frequency $1 \mathrm{~Hz}, \mathrm{SS} 2$ geogrid between base course and sand

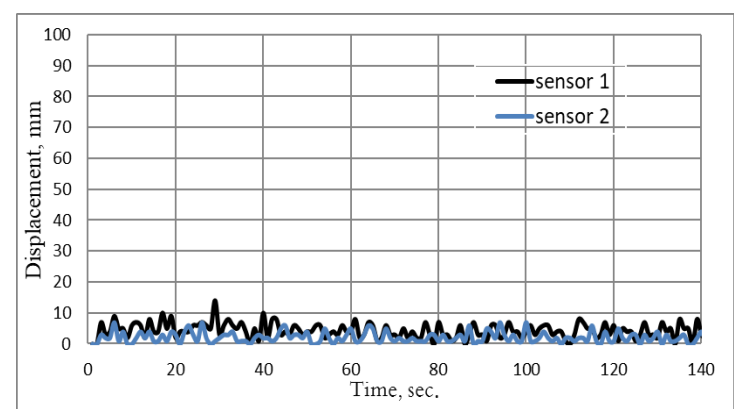

Figure 20: Variation of displacement in road layers under frequency $1 \mathrm{~Hz}, \mathrm{SS} 2$ geogrid at the center of base course layer

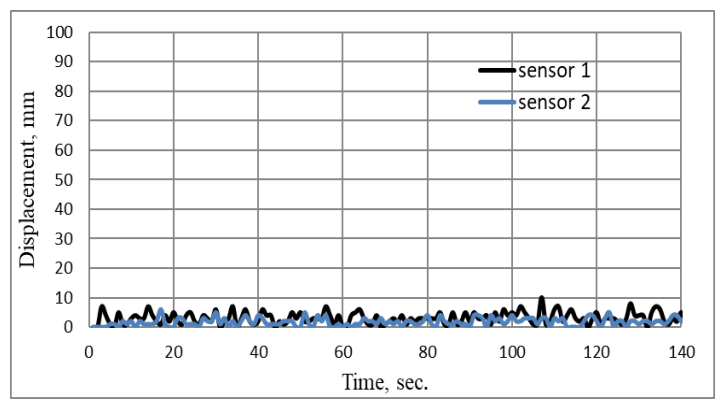

Figure 22: Variation of horizontal displacement in road layers under frequency $0.5 \mathrm{~Hz}, \mathrm{SS} 2$ geogrid between base course and sand

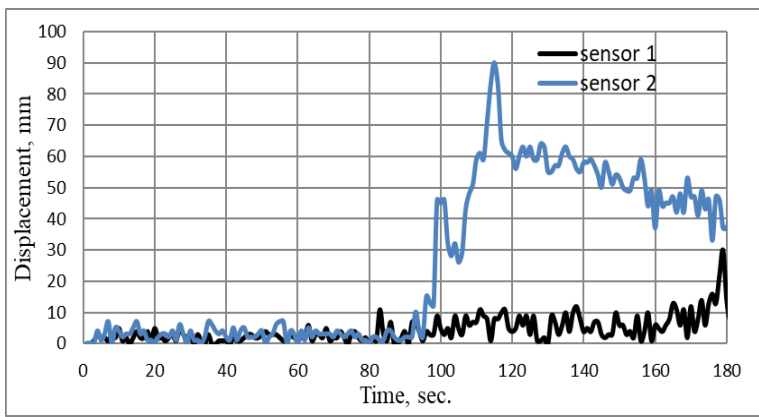

Figure 24: Variation of horizontal displacement in road under frequency $1.5 \mathrm{~Hz}, \mathrm{SS} 2$ geogrid between base course and sand 
Table 4: Summary of maximum stress and maximum displacement at each case.

\begin{tabular}{|c|c|c|c|c|c|c|}
\hline \multirow[t]{2}{*}{ Case } & \multirow{2}{*}{$\begin{array}{c}\text { Frequency } \\
(\mathrm{Hz})\end{array}$} & \multirow[t]{2}{*}{ Layer } & \multicolumn{2}{|c|}{ Max. stress } & \multicolumn{2}{|c|}{ Max. displacement } \\
\hline & & & $\begin{array}{l}\text { Value } \\
(\mathrm{kPa})\end{array}$ & $\begin{array}{c}\begin{array}{c}\text { Time of } \\
\text { occurrence } \\
\text { (sec) }\end{array} \\
\end{array}$ & $\begin{array}{l}\text { Value } \\
(\mathbf{m m})\end{array}$ & $\begin{array}{c}\begin{array}{c}\text { Time of } \\
\text { occurrence } \\
\text { (sec) }\end{array} \\
\end{array}$ \\
\hline \multirow{3}{*}{ Without geogrid } & 0.5 & Base course & 361.51 & 44 & 19 & 21 \\
\hline & 1 & Base course & 373.27 & 54 & 95 & 91 \\
\hline & 1.5 & Base course & 401.25 & 3 & 83 & 51 \\
\hline \multirow{3}{*}{$\begin{array}{l}\text { With geogrid at the } \\
\text { middle of the base }\end{array}$} & 0.5 & Base course & 328.54 & 97 & 9 & 59 \\
\hline & 1 & Base course & 647.24 & 75 & 14 & 28 \\
\hline & 1.5 & Base course & 402.25 & 7 & 82 & 51 \\
\hline \multirow{3}{*}{$\begin{array}{l}\text { With geogrid } \\
\text { between the base } \\
\text { and the subgrade }\end{array}$} & 0.5 & Base course & 698.85 & 1 & 10 & 106 \\
\hline & 1 & Asphalt & 816.84 & 33 & 10 & 67 \\
\hline & 1.5 & Asphalt & 799.83 & 49 & 90 & 115 \\
\hline
\end{tabular}

\section{Conclusions}

Given the outcomes acquired from the model tests performed on the different variables to think about the impact of the earthquake on the road layers, the following conclusions could be obtained:

1. The results of tests on pavement layers proved that in models reinforced with geogrid, the stress recorded is higher than in unreinforced models, while the displacement recorded at frequency $1.5 \mathrm{~Hz}$ is lower than that recorded under frequency $1 \mathrm{~Hz}$.

2. Adding geogrid reinforcement in the center of the base layer and between the base course and sand layer showed an increase of transmitted stress and decrease in displacement with the increase in frequency from 0.5 to $1 \mathrm{~Hz}$. Also, under frequency $1.5 \mathrm{~Hz}$, the maximum stress decreases but the displacement increases.

3. When the geogrid is laid between the base course and sand layer, the stress in the sand subgrade layer is less than that in the base and asphalt layers.

Author contribution

All authors contributed equally to this work.

Funding

This research received no specific grant from any funding agency in the public, commercial, or not-for-profit sectors.

Data availability statement

The data that support the findings of this study are available on request from the corresponding author.

Conflicts of interest

The authors declare that there is no conflict of interest.

\section{References}

[1] Salih, S. M., Stress Transfer and Distribution in Reinforcement under Footings on Reinforced Earth, M.Sc. thesis., College of Engineering, Al-Mousl University, Iraq, 1989.

[2] Al-Qadi, I.L. and Appea, A. K. ,Eight-Year of Filed Performance of a Secondary Road Incorporating Geosynthetics at the Subgrade-Base Interface., Transportation Research Board, 82rd Annual Meeting Washington D.C, 2003.

[3] Holder , W. H. and Andreae, J., Geogrid Reinforcement to Reduce Pavement Section Thickness: A Case Study, ASCE, Conference Proceedings Paper, Geotechnical Engineering for Transportation Projects, (GSP 126) Reston, Va., 1006-1024, 2004.

[4] Edil, T. B. , Kim, W. , Benson, C. H. and Tanyu B.F., Contribution of Geosynthetic Reinforcement to Granular Layer Stiffness. ASCE, Conference Proceeding Paper, Soil and Material Inputs for Mechanistic Empirical Pavement Design GSP 169 (2007) 1-11. http://dx.doi.org/10.1061/40913(232)1

[5] H. Y., Jeon, Theoretical Approach of Long-term Behaviors of Geogrids, the 12th international Conference of International Association for Computer Methods and Advances in Geomechanics (IACMAG), 1-6 October, Goa, India, 2008.

[6] J. G. Zornberg, J. A. Prozzi, R. Gupta, R. Luo, J. S. McCartney, J. Z. Ferreira, and C. Nogueira, Validating Mechanisms in Geosynthetic Reinforced Pavements, Center for Transportation Research (CTR), Report No. 0-4829-1, Austin, Texas, February, 2008. 
[7] D. S. V. Prasad, K. M. Anjan, R. G. V. R. Prasada, V. Kondayya, Behaviour of Flyash Reinforced Sub-bases on Expansive Soil Subgrades under Cyclic Loading, Indian Geotechnical Conference-2010, GEOtrendz December 16-18, IGS Mumbai Chapter IIT Bombay, 727730, 2010.

[8] A. K., Choudhary, K. S. Gill and J. N. Jha, J.N., Improvement in CBR Values of Expansive Soil Sub-grades using Geosynthetics, Indian Geotechnical Conference December 15-17, 2011, Kochi (Paper No. J-233), 2011.

[9] H. C. Dan, D. Yang, X. Liu, A. P. Peng, Z. Zhang, Experimental Investigation on Dynamic Response of Asphalt Pavement Using SmartRock Sensor under Vibrating Compaction Loading, Constr. Build. Mater., 247 (2020) 118592, https://doi.org/10.1016/j.conbuildmat.2020.118592,2020

[10] ASTM Book of Standards, American Society for Testing and Materials, 2017.

[11] SCRB/R9, General Specification for Roads and Bridges, Section R/9, Hot-Mix Asphalt Concrete Pavement, Revised Edition. State Corporation of Roads and Bridges, Ministry of Housing and Construction, Republic of Iraq, 2003.

[12] M. M. Hussein, M. Y. Fattah, M. M. Hilal, M. M., Transmission of Stresses in Pavement Layers Subjected to Earthquake Excitation, 4th International Conference on Engineering Sciences (ICES 2020), IOP Conf. Series: Materials Science and Engineering, IOP., 1067 (2021) 012060, https://doi.org/10.1088/1757-899X/1067/1/012060, 2021

[13] W. N., Abdulkhabeer, M. Y. Fattah, M. M. Hilal, Characteristics of Asphalt Binder and Mixture Modified With Waste Polypropylene, Eng. Technol. J., 39 (2021) 1224-1230. http://doi.org/10.30684/etj.v39i8.1716, 2021

[14] A. I. K. Al-Utabi, An Approach In Improving Unpaved Roads Overlying Soft Clay Soils Using Geogrid, M.Sc, thesis, College of Engineering, Al-Mustansiryia University, Iraq, 2011.

[15] K., Reddy, 'Influence of Subgrade Condition on Rutting in Flexible Pavements- an Experimental Investigation', International Journal of Civil, Eng. Technol. J., 4 (2013) 30-37.

[16] Z. T. Teama, Suitability of Dune Sands Subgrade Beneath Flexible Pavement Structure under Repeated Loads, M.Sc, thesis, College of Engineering, Al-Mustansiryia University, Iraq, 2014.

[17] Tensar International, Railways-Reinforcing Ballast under Railway Track, Technical Publications, 2001.

[18] M. K., Al-Rcaby, Dynamic Response to Lateral Excitation of Pile Group Model in Sandy Soil, Ph.D. thesis., Building and Construction Engineering Department, University of Technology, Baghdad, Iraq, 2016.

[19] M. Y. Fattah, A. S. Aladili, H. F. Yousif, Investigation of Reinforced Sub-base Layer on Saturated Expansive Subgrade Soil under Cyclic Loading, Int. J. Earth Sci. Eng., 10 (2017) 604-615. http://doi.org/10.21276/ijee.2017.10.0319

[20] M. Y. Fattah, M. R Mahmood, M. F. Aswad, Experimental and Numerical Behavior of Railway Track Over Geogrid Reinforced Ballast Underlain by Soft Clay, Proceedings of the 1st GeoM East International Congress and Exhibition, Egypt 2017 on Sustainable Civil Infrastructures, Recent Developments in Railway Track and Transportation Engineering, 14 (2017) 1-26. https://doi.org/10.1007/978-3-319-61627-8_ 1

[21] M. Y. Fattah, H. H. Alwash, S. A. Hadi, Behavior of Khassa Chai Earth Dam under Earthquake Excitation, Eng. Technol. J., 34 (2016) 2784-2795. http://dx.doi.org/10.30684/etj.34.15A.1

[22] A. M. Raheem, M. Y. Fattah, M. K. Al-Recaby, Earthquake Response of Model Footings on Soft Clays Strengthened by Stone Columns, Eng. Technol. J., 39 (2021)1216-1223. http://doi.org/10.30684/etj.v39i8.1651, 2021 